\title{
PRÁTICAS DE GESTÃO DA QUALIDADE, ESTRATÉGIAS COMPETITIVAS E DESEMPENHO INOVADOR NA INDÚSTRIA DE TRANSFORMAÇÃO BRASILEIRA
}

\section{RESUMO}

O objetivo geral deste estudo foi analisar a relação entre orientação estratégica da empresa, práticas de gestão da qualidade e desempenho inovador, no contexto de empresas da indústria de transformação brasileira. A pesquisa é quantitativa, sendo aplicada a estratégia da survey comum a amostra de 65 empresas, com uso de questionário, enviado por e-mail. Os dados coletados foram analisados por meio da análise de regressão múltipla. Constatou-se que as práticas de TQM Hard são as que exercem maior influência sobre o desempenho inovador, em especial, sobre a inovação por processo. A estratégia de diferenciação tem maior impacto sobre a inovação, do que a estratégia de liderança em custos. Ao mesmo tempo, está mais relacionada com a adoção das práticas de TQM Hard e Soft. Como conclusão, verificou-se que no contexto das empresas investigadas, a gestão da qualidade é aplicada como uma das bases de diferenciação, sendo tratada como fonte de vantagem competitiva.

Palavras-chave: Gestão da Qualidade; Estratégia Competitiva; Inovação; Indústria.

\section{QUALITY MANAGEMENT PRACTICES, COMPETITIVE STRATEGIES AND INNOVATIVE PERFORMANCE IN THE BRAZILIAN INDUSTRY TRANSFORMATION}

\section{ABSTRACT}

The aim of this study was to analyze the relationship between strategic orientation of the company, quality management practices and innovative performance in the context of companies in the Brazilian manufacturing industry. The research is quantitative, and was applied to the survey strategy with a sample of 65 companies, with use of a questionnaire, sent by email. Data were analyzed using multiple regression analysis. It was found that the practices of TQM Hard have greater influence on the innovation performance, in particular on innovation by process. The differentiation strategy has the greatest impact on innovation than the strategy of leadership in costs. At the same time, it is more related to the adoption of practices of TQM Hard and Soft. In conclusion, it was found that in the context of the investigated companies, quality management is applied as a differentiation of bases, being treated as a source of competitive advantage.

Keywords: Quality Management; Competitive Strategy; Innovation; Industry. 
Práticas de Gestão da Qualidade, Estratégias Competitivas e Desempenho Inovador na Indústria de Transformação Brasileira

\section{PRÁCTICAS DE GESTIÓN DE CALIDAD, ESTRATEGIAS COMPETITIVAS Y DESEMPEÑO INNOVADOR EN LA TRANSFORMACIÓN INDUSTRIA BRASILEÑA}

\section{RESUMEN}

El objetivo de este estudio fue analizar la relación entre la orientación estratégica de la empresa, las prácticas de gestión de la calidad y el rendimiento innovador en el contexto de las empresas en la industria de fabricación brasileña. La investigación es cuantitativa y se aplicó a la muestra de la encuesta estrategia común de 65 empresas, con el uso de un cuestionario, enviado por correo electrónico. Los datos fueron analizados mediante el análisis de regresión múltiple. Se encontró que las prácticas de GCT duro están ejerciendo una mayor influencia en los resultados de innovación, en particular, en la innovación de proceso. Estrategia de diferenciación tiene el mayor impacto en la innovación de la estrategia de liderazgo en costes. Al mismo tiempo, se está más relacionado con la adopción de prácticas de GCT duros y blandos. En conclusión, se encontró que en el contexto de las empresas investigadas, se aplica la gestión de la calidad como una diferenciación de bases siendo tratada como una fuente de ventaja competitiva.

Palabras clave: Gestión de Calidad; Estrategia Competitiva; La Innovación; Industria.

\footnotetext{
${ }^{1}$ Doutoranda em Administração e Controladoria pela Universidade Federal do Ceará - UFCE. Professora do Centro Universitário Estácio do Ceará. Tutora a distância do Instituto UFC Virtual.. Brasil. E-mail: vivianne.roldan2016@gmail.com

${ }^{2}$ Doutor em Administração de Empresas pela Escola de Administração do Estado de São Paulo da Fundação Getulio Vargas - EAESP/FGV. Professor da Universidade Federal do Ceará - UFCE. Brasil. E-mail: sfsf@ uol.com.br
} 


\section{INTRODUÇÃ̃O}

A adoção do sistema de gestão da qualidade, por meio da certificação ISO 9001, continua sendo procurada pelas organizações, como meio de obtenção de vantagem competitiva, desde sua vigência em 1987. Dentre as motivações para sua implantação estão, a redução de custos, a geração de eficiência dos processos, melhoria da reputação da empresa e criação de valor para os clientes.

No Brasil, a Associação Brasileira de Normas Técnicas [ABNT] é o órgão que coordena a elaboração e adaptação das normas internacionais, como a ISO 9001. Para obtenção da certificação, as empresas brasileiras deverão procurar as certificadoras acreditadas pelo Instituto Nacional de Metrologia e Qualidade Industrial [INMETRO]. A adoção da certificação no país é voluntária, e ter um certificado significa que a empresa possui um sistema gerencial voltado para a qualidade.

Dentre as várias modificações ao longo do tempo, recentemente a norma ISO 9001, no Brasil, sofreu mais uma alteração, sendo substituída a versão ISO 9001/2008 para a versão ISO 9001/2015.Empresas de qualquer porte e setor de atuação podem se beneficiar com a certificação do sistema de gestão da qualidade (Bsigroup, 2016; Esperança et al., 2015).

A alteração introduziu novos aspectos à norma, podendo ser destacados: a introdução da avaliação de riscos como base para o sistema de gestão; maior ênfase na liderança e comprometimento da alta administração; maior ênfase no contexto organizacional, e na geração de valor para a organização e clientes; melhor aplicabilidade para o setor de serviços; maior flexibilidade relativa à documentação; maior ênfase no planejamento e controle de mudanças; introdução de cláusula sobre gestão do conhecimento organizacional (Bsigroup, 2016; Esperança et al., 2015).

A inovação tem sido destacada, por autores como Boiral (2012), como um dos benefícios organizacionais gerados pela implantação de um sistema de gestão da qualidade. $\mathrm{O}$ autor realizou uma revisão de resultados de 111 estudos que mensuraram o impacto do sistema de gestão da ISO 9001 no desempenho organizacional, no período de 1994 a 2008, destacando-se a inovação como um dos impactos internos gerado pela certificação.

No entanto, os reais benefícios da certificação ainda são objetos de controvérsias para gestores e acadêmicos, contribuindo para a geração de diversos estudos que buscam confirmar ou refutar os benefícios em discussão (Boiral, 2012).

A inovação é um dos fatores discutidos nos estudos empíricos, onde não há consenso entre os acadêmicos de que práticas de gestão da qualidade pode contribuir para aumentar o desempenho inovativo das empresas. Alguns estudiosos chegaram à conclusão de que a sua aplicação aumenta a burocracia, reduzindo a inovação, ou de que afeta positivamente a atenção a detalhes e a adesão as regras, mas que isso incorre em detrimento da inovação de produtos (Krivokapic, 2013).

Outros autores, como Wright et al. (2012) discordam desse posicionamento, defendendo que a normalização trazida por práticas de gestão da qualidade pode contribuir positivamente para a inovação, pois a criação de linguagens e metodologias comuns podem promover um processo de melhoria incremental baseado no aprendizado anterior. Os autores destacam estudos empíricos que defendem seu ponto de vista, e a visão de críticos de que a gestão da qualidade beneficiaria somente a formas específicas de inovações, em detrimento de outras, mais exploratórias.

Ao mesmo tempo, uma outra corrente de estudos, apesar de restrita, tem buscado analisar a relação entre as práticas da gestão da qualidade e a estratégia competitiva nas organizações. Questiona-se se as práticas de gestão da qualidade estão mais associadas a uma estratégia de liderança em custos, a estratégia de diferenciação ou ambas ao mesmo tempo (Prajogo, 2007; Prajogo \& Sohal, 2006). Noutra direção, alguns pesquisadores buscaram avaliar também como essas estratégias competitivas estão associadas ao desempenho inovador das empresas.

Partindo do pressuposto de que a orientação estratégica da organização é um fator determinante para a definição da abordagem de gestão de qualidade a ser aplicada na empresa (Belohlav, 1993; Prajogo, 2007; Prajogo \& Sohal, 2006), e que isso trará implicações sobrea ênfase relacionada à inovação, esta pesquisa pretendeu responder ao seguinte problema: Qual a relação entre orientação estratégica da empresa, práticas de gestão da qualidade e desempenho inovador, no contexto de indústrias brasileiras de transformação?

As abordagens específicas de gestão da qualidade se referem às ênfases a princípios e práticas que irão se diferenciar conforme seu setor de atuação, tamanho, contexto externo, entre outras variáveis situacionais (Leavengood, Anderson \&Daim, 2014; Mintzberget al., 2006).

Partindo do problema da pesquisa, o objetivo geral deste estudo foi analisar a relação entre orientação estratégica da empresa, práticas de gestão da qualidade e desempenho inovador, no contexto de empresas da indústria de transformação brasileira.

Como objetivos específicos, pretendeu-se: 1) Investigar a influência das Práticas de TQM sobre o desempenho inovador; 2) Verificar a influência da orientação estratégica das organizações sobre seu desempenho inovador; 3) Analisar a relação entre a orientação estratégica das empresas e o tipo de práticas de TQM adotadas.

Para o alcance dos objetivos do estudo, foram testadas as seguintes hipóteses: 
H1: Práticas TQM Soft impactam positivamente na inovação por produtos;

H2: Práticas TQM Hard impactam positivamente na inovação por processos;

H3: A Estratégia de diferenciação exerce maior influência sobre a inovação por produtos;

H4: A Estratégia de Liderança em custos exerce maior influência sobre a inovação por processos;

H5: A Estratégia de liderança em custos exerce maior influência para a adoção de Práticas de TQM Hard;

H6: A Estratégia de Diferenciação exerce maior influência para a adoção de Práticas de TQM Soft.

Esse artigo está organizado em sete seções. As três primeiras seções se referem à conceituação da gestão de qualidade e classificação de suas práticas, a relação entre práticas de gestão da qualidade e estratégia competitiva, e entre gestão da qualidade e desempenho inovador. As seções seguintes apresentam os procedimentos metodológicos adotados neste estudo, os resultados gerados e sua discussão, finalizando com as conclusões.

\section{GESTÃO DA QUALIDADE: CONCEITUAÇÃO E TAXONOMIA}

Desde a década de 80, a Gestão da Qualidade Total [TQM] tem sido reconhecida como fator de geração de vantagem competitiva, ajudando as organizações a ofertarem produtos e serviços de alta qualidade para seus consumidores. Apesar de ser um conceito amplamente adotado no mundo, em especial, nas indústrias, ainda existem problemas a serem sanados para o alcance satisfatório de sua finalidade.

A TQM tem sido tratada ora como uma filosofia de gestão, como um modelo, um sistema, ou uma abordagem de gestão. Uma das primeiras definições foi apresentada por Dean \&Bowen (1994) que a definiram como uma filosofia de gestão, ou uma abordagem de gestão composta por princípios, práticas e técnicas (Dahlgaard-parket al., 2013).

Hellsten \& Klefsjö (2000) consideraram a TQM como um sistema de gestão composto por três elementos interdependentes: os valores fundamentais, que consistem nas normas e valores que orientam o comportamento dos membros da organização; e as ferramentas e técnicas que deverão contribuir para a realização desses valores (Dahlgaard-park et al., 2013).

Lakhe \& Mohanty (1994) destacam o que consideram conceitos chaves da gestão da qualidade total: uma abordagem para aumentar a efetividade e flexibilidade do negócio; uma forma de organizar e de envolver toda a organização; a integração de vários processos que irão caracterizar a dinâmica comportamental da empresa; um sistema sócio técnico que busca fazer tudo certo internamente, para fazer as coisas certas externamente, durante todo o tempo e com viabilidade econômica; um esforço integrado para ganho de vantagem competitiva, por meio da melhoria contínua de todas as facetas da cultura organizacional.

Para Dahlgaard-Park et al. (2013), a gestão da qualidade evoluiu de uma ferramenta estreita e somente orientada para a técnica, para uma filosofia gerencial ou sistema de gestão holístico que abrange como questões centrais, a eficiência, a qualidade de vida no trabalho e a eficácia. A eficiência se fundamenta nas tradições do controle estatístico de processos, engenharia de processos, gestão de operações e pesquisa operacional, com foco na melhoria contínua.

A qualidade de vida no trabalho se refere à gestão dos recursos humanos, no que concerne à capacitação, trabalho em equipe e motivação. Por sua vez, a eficácia tem como base a escola de gestão estratégica, onde se trabalha com preocupações relativas a alcance de metas, participação no mercado, sobrevivência e lucratividade. Dahlgaard-Park et al. (2013) considera a TQM como a primeira abordagem de gestão que conseguiu abranger três áreas chaves: gestão de processos e de operações, gestão de recursos humanos e gestão estratégica.

A TQM tornou-se uma abordagem de gestão abrangente que engloba, portanto, várias camadas e elementos, o que faz com que as partes interessadas envolvidas tenham uma certa dificuldade de compreendê-lo quanto fenômeno (Dahlgaard-Park et al., 2013).

A gestão da qualidade total pode ganhar significados diferentes para pessoas diferentes, por ter sido incorporado em mais de um tipo de organização, cada qual situada em contexto distinto. Para compreensão da abordagem da gestão da qualidade em determinada empresa, Sousa \& Voss (2002) sugerem que sua análise seja feita a nível de práticas e não de princípios, pois estes últimos são muito abrangentes para uma investigação empírica, enquanto as práticas são uma faceta mais observável da TQM.

Em termos de princípios, a TQM se fundamenta em três itens essenciais: 1) foco sobre consumidores e stakeholders; 2) participação e trabalho em equipe em toda organização; 3) Foco no processo fundamentado na melhoria contínua e aprendizado (Leavengood et al., 2014).

As práticas de gestão de qualidade têm sido definidas de maneiras distintas entre os pesquisadores, mas se complementam. Essas práticas podem ser definidas, na visão de Oakland (1995), como as áreas críticas que a organização deve focar em termos de execução e de avaliação, para conseguir cumprir a sua missão; ou na perspectiva de Boynton \& Zmud (1984) são as práticas representadas pelas áreas gerenciais ou organizacionais para as quais devem ser dadas maior atenção para garantia do sucesso da organização; Brotherton \& Shaw (1996), por sua vez, defende que essas práticas não devem ser compreendidas como objetivos, mas como ações e processos essenciais, que 
alcançados, garantirão vantagem competitiva (Talib, 2013).

Sousa \& Voss (2002) compara cinco estudos sobre as principais dimensões de práticas de TQM, e verifica que existe um consenso substancial entre os estudos sobre essas dimensões, que estão todas presentes nos quadros desenvolvidos por premiações nacionais de qualidade, tais como o Prêmio Nacional da Qualidade Malcolm Baldrige nos EUA e o Prêmio Europeu da Qualidade. Para esses autores, isso demonstra um amadurecimento do campo, definido em fundações sólidas.

No entanto, autores como Talib (2013) não concordam com esse posicionamento, e afirmam que apesar da existência desses modelos para premiação das empresas que podem ser usados como um quadro útil para ajudá-las na implementação da TQM, e avaliar seu desempenho, não se pode afirmar que exista um pleno consenso sobre quais práticas levam a uma implementação bem-sucedida da TQM.

As pesquisas sobre TQM têm explorado o conceito de dualidade, sendo uma das classificações a de Wilkinson (1992), onde as práticas de qualidade são divididas em práticas rígidas ou tangíveis (hard) e práticas intangíveis (soft). As práticas de TQM soft se referem aos aspectos comportamentais da gestão da qualidade, enquanto as práticas de TQM hard consistem nos aspectos técnicos (Zeng, Phan \& Matsui, 2015).

As práticas hard incidem sobre o controle de processos e produtos para que atendam as conformidades e requisitos estabelecidos, por meio da aplicação de técnicas e ferramentas. As práticas soft têm como foco a promoção do envolvimento e comprometimento dos gestores e colaboradores, do trabalho em equipe, da capacitação, e aprendizado (Zenget al., 2015; Dahlgaard-Park et al., 2013).

Ainda não existem consenso entre os achados sobre qual dimensão de TQM (hard ou soft) tem maior importância sobre o desempenho da organização (Zenget al., 2015; Guerra \& Tondolo, 2015). Também não há um modelo único consolidado pelos pesquisadores acerca dos fatores que podem ser categorizados como práticas Hard e Soft da TQM (Guerra \& Tondolo, 2015).

Os quadros a seguir, apresentam as dimensões de práticas de qualidade mais trabalhadas pelos pesquisadores nos diversos estudos empíricos sobre desempenho organizacional, ora categorizadas em práticas Hard e Soft. São poucos ainda os estudos que relacionam o sistema de gestão de qualidade com o desempenho de natureza inovador, que é o enfoque do presente estudo.

A alocação das dimensões de práticas de TQM encontradas na literatura, em práticas Hard e Soft, foi inspirada no estudo de Cua et al. (2001), que definem como práticas técnicas básicas de qualidade (Hard), as dimensões Design de produto, Gestão de Processos, Gestão da Qualidade de Fornecedores, e Envolvimento do Cliente. Como práticas de orientação estratégica e humanas (Soft), os autores definem: comprometimento da liderança, planejamento estratégico, treinamento, e envolvimento dos empregados.

\begin{tabular}{|c|c|}
\hline Dimensões da TQM & Autores \\
\hline Gestão de Processos & $\begin{array}{l}\text { Prajogo \& Sohal (2003), Prajogo \& Sohal (2004), Nair (2006), } \\
\text { Honarpour, Jusoh, \& Nor (2012), Talib, Rahman \& Qureshi (2013), } \\
\text { Fernandes, Lourenço \& Silva (2014), Wong \& Lee (2014), Zhang, } \\
\text { Linderman \& Schroeder (2014), Sinha, Garg \& Dhall (2016) }\end{array}$ \\
\hline Foco no Cliente & $\begin{array}{l}\text { Prajogo \& Sohal (2003), Prajogo \& Sohal (2004), Nair (2006), } \\
\text { Honarpour et al. (2012), Talib et al. (2013), Fernandes et al. (2014), } \\
\text { Wong \& Lee (2014), Zhanget al.(2014), Sinhaet al. (2016) }\end{array}$ \\
\hline Gestão e design de produto & Nair (2006), Talibet al. (2013), Fernandes et al. (2014) \\
\hline Relação com fornecedores & $\begin{array}{l}\text { Nair (2006), Honarpour et al. (2012), Talib et al. (2013), Fernandes et } \\
\text { al. (2014), Zhang et al. (2014), Sinha et al. (2016) }\end{array}$ \\
\hline Sistemas de qualidade & Talib et al. (2013) \\
\hline Benchmarking & Talib et al. (2013) \\
\hline Melhoria contínua & Talib et al. (2013), Fernandes et al. (2014), Sinha et al. (2016) \\
\hline
\end{tabular}

Quadro 1 - Dimensões de Práticas Hard da TQM

Fonte: Revisão de literatura (2016). 
Práticas de Gestão da Qualidade, Estratégias Competitivas e Desempenho Inovador na Indústria de Transformação Brasileira

\begin{tabular}{|c|c|}
\hline Dimensões da TQM & Autores \\
\hline $\begin{array}{c}\text { Comprometimento da Alta } \\
\text { Administração }\end{array}$ & Talibet al. (2013), Mehmood et al. (2014) \\
\hline Gestão da Liderança & $\begin{array}{l}\text { Prajogo \& Sohal (2003), Prajogo \& Sohal(2004), Nair (2006), } \\
\text { Honarpour et al. (2012), Fernandes et al. (2014), Wong \& Lee } \\
\text { (2014), Zhang et al. (2014), Sinha et al. (2016) }\end{array}$ \\
\hline Planejamento estratégico & $\begin{array}{l}\text { Prajogo \& Sohal (2003), Prajogo \& Sohal (2004), Talib et al. (2013), } \\
\text { Wong \& Lee (2014) }\end{array}$ \\
\hline $\begin{array}{l}\text { Informação e análise/Gestão } \\
\text { do conhecimento }\end{array}$ & $\begin{array}{l}\text { Prajogo \& Sohal (2003), Prajogo \& Sohal (2004), Nair (2006Talibet } \\
\text { al. (2013), Fernandes et al. (2014), Wong \& Lee (2014) }\end{array}$ \\
\hline Gestão de pessoas & $\begin{array}{l}\text { Prajogo \& Sohal (2003), Prajogo \& Sohal (2004), Nair (2006), } \\
\text { Honarpour et al (2012), Fernandes et al. (2014), Wong \& Lee (2014), } \\
\text { Zhang et al. (2014), Sinha et al. (2016) }\end{array}$ \\
\hline Cultura da qualidade & Talib et al. (2013) \\
\hline
\end{tabular}

Quadro 2 - Dimensões de Práticas Soft da TQM

Fonte: Revisão de literatura (2016).

\section{GESTÃO DA QUALIDADE E DESEMPENHO INOVADOR}

O desempenho da organização tem recebido tratamentos distintos em muitos estudos. Alguns pesquisadores mensuram o desempenho de natureza financeira, como lucratividade, participação no mercado, retorno sobre investimento. Outros avaliam o desempenho operacional da organização, em termos de qualidade de produtos e processos, ou investigam o desempenho referente à satisfação do consumidor. São diversos os termos utilizados: desempenho corporativo, desempenho do negócio, desempenho de qualidade, desempenho não financeiro (Nair, 2006; Tanet al.,2014).

Em alguns estudos, o desempenho organizacional é tratado como um constructo multidimensional, e outros o consideram um constructo simples (Nair, 2006).

No presente estudo, está sendo abordado o desempenho inovador, referente aos componentes resultantes da inovação, dentre eles, a inovação de produto, a inovação do processo e a inovação organizacional (Pires, 2013). Fernandes et al. (2014), sintetizaram esses componentes, conforme disposto a seguir:

\begin{tabular}{|c|l|}
\hline Componentes da Inovação & \multicolumn{1}{c|}{ Descrição } \\
\hline Inovação do produto & $\begin{array}{l}\text { Introdução de um bem ou serviço novo, ou significativamente } \\
\text { melhorado, no mercado }\end{array}$ \\
\hline Inovação do processo & $\begin{array}{l}\text { Referente a introdução de um processo novo ou melhorado na } \\
\text { produção do produto/serviço }\end{array}$ \\
\hline Inovação organizacional & Implementação de um novo método organizacional \\
\hline Inovação da gestão & Implementação de um novo método de gestão \\
\hline Inovação tecnológica & $\begin{array}{l}\text { Referente à inovação da tecnologia, por meio da existência de } \\
\text { centro de investigação e desenvolvimento tecnológico }\end{array}$ \\
\hline Inovação de marketing & Implementação de um novo método de marketing \\
\hline
\end{tabular}

Quadro 3 - Componentes resultantes da Inovação

Fonte: Adaptado de Fernandes et al. (2014, p.580).

Os argumentos sobre a relação entre gestão da qualidade e inovação são conflitantes. Alguns argumentos defendem que os princípios da gestão da qualidade não são compatíveis com a inovação, afirmando que a filosofia de melhoria contínua se centra na simplificação e racionalização do processo, para estabelecer controle e estabilidade. A inovação é tratada como um processo de mudança contínua, muito rápida para ser padronizada, o "novo" sem precedentes (Zeng, Phan \& Matsui, 2015; Wright, Sturdy \& Wylie, 2012).

As pessoas são conduzidas a focar mais nos detalhes do processo de qualidade, do que em gerar novas ideias que possam transformar o sistema de 
trabalho atual. Dessa forma, as práticas de gestão de processos da qualidade, que focam a redução do desperdício e melhoria da eficiência, seriam prejudiciais para a inovação, por não abrirem folga para o seu desenvolvimento. Representariam assim, gaiolas de ferro de regulação e controle organizacional (Zeng et al., 2015; Wright et al., 2012).

Nessa linha, alguns estudiosos criticam o argumento de foco no cliente como uma fonte de inovação, pois acreditam que ele possa estreitar a mentalidade das empresas sobre os produtos e serviços atuais, ao invés de contribuir para a geração de melhorias inovadoras (Zeng et al., 2015).

Uma outra corrente de acadêmicos defende que os sistemas de qualidade e inovação são amplamente compatíveis e complementares entre si. A gestão da qualidade torna a organização mais orientada para objetivos e melhor preparada para responder as mudanças internas e externas, tornando-a mais aberta para a inovação. Uma relação conflitante entre esses sistemas adviria de uma implantação ineficaz do sistema de gestão da qualidade. Somente as organizações com um TQM eficaz e eficiente estarão mais predispostas a inovar (Krivokapic et al., 2013).

Para essa corrente, a gestão da inovação é assistida pela padronização, que cria linguagens e metodologias comuns de investigação e experimentação, promovendo a melhoria incremental baseada nas experiências anteriores. Destaca-se que isso ocorre quando a abordagem de qualidade enfatiza a melhoria do desempenho nas atividades, ao invés do seu controle propriamente dito. A difusão da gestão da inovação e competitividade organizacional são dependentes da padronização de modelos de gestão normativos, como a TQM. A implementação da inovação será seguida pela padronização dos novos produtos e serviços gerados, bem como de práticas comerciais, o que ocorre, por exemplo, em empresas de gestão de moda (Wright et al., 2012).

Dentre os acadêmicos que defendem essa corrente, podem ser citados Bessant et al. (2005), que defendem que empresas que adotam sistemas de gestão da qualidade total são mais propensas a inovar.

Uma terceira perspectiva compreende a relação entre gestão da inovação e padronização como ambivalentes. Aqui a concepção de inovação reconhece a novidade como algo relativo, ou seja, que pode advir do já conhecido em nível geral, e ser considerado altamente inovador por um gestor, empresa ou setor específico. A gestão da inovação é compreendida como algo subjetivamente novo e advinda da reinvenção ao longo do tempo, por meio da mudança incremental (Wright et al., 2012).

É importante pontuar que em algumas organizações o próprio processo de gestão da inovação é padronizado, enquanto em outras empresas não é adotado um modelo de gestão para essa finalidade. Existem estudos empíricos que indicam que empresas que adotam modelos padronizados de gestão da inovação tem melhor desempenho (Kobe,Verworn \& Meier, 2005).

Os achados sobre a relação entre práticas de TQM e desempenho inovador, ainda são contraditórios entre si. Alguns resultados demonstram uma influência direta da gestão da qualidade sobre o desenvolvimento de inovações, outros apontam uma relação indireta. Em geral, é visualizado que a gestão da qualidade impacta positivamente determinadas zonas de desempenho da inovação, apesar de existirem estudos empíricos onde não foi encontrada nenhuma relação positiva e significante.

O quadro a seguir sumariza os resultados de estudos empíricos sobre os componentes do desempenho inovador que apresentaram relação positiva com as práticas de gestão da qualidade.

\begin{tabular}{|c|l|}
\hline \multirow{2}{*}{ Componentes do desempenho inovador } & \multicolumn{1}{|c|}{ Autor(es) } \\
\hline & $\begin{array}{l}\text { Silva } \text { et al. (2014), Fernandes } \text { et al. (2014), Prajogo \& Sohal } \\
\text { (2003), Prajogo \& Sohal (2004), Hoanget al (2006), Prajogo \& } \\
\text { Hong (2008), Pekovic \& Galia (2009), Vahidnia, Bavarsad \& } \\
\text { Senoubari (2013),Bigliardi \& Galati (2014), Zeng } \text { et al. (2015) }\end{array}$ \\
\hline Inovação do produto & $\begin{array}{l}\text { Prajogo \& Sohal (2003), Pekovic \& Galia (2009), Fernandes } \text { et al. } \\
\text { (2014), Terziovski \& Guerrero (2014) }\end{array}$ \\
\hline Inovação do processo & $\begin{array}{l}\text { Martinez-Costa \& Martinez-Lorente (2008), Pekovic \& Galia } \\
\text { (2009), Hunget al. (2011), Honarpour, Jusoh \& Nor (2012), Kim, } \\
\text { Kumar \& Kumar (2012), Long } \text { et al. (2015) }\end{array}$ \\
\hline Inovação do Processo e Produto & Fernandes et al. (2014), Hung et al. (2011) \\
\hline Inovação organizacional & $\begin{array}{l}\text { Fernandes } \text { et al. } \text { (2014), Santos-Vijande \& Alvarez-Gonzalez } \\
\text { (2007), Ruiz-Moreno } \text { et al. } \text { (2016) }\end{array}$ \\
\hline Inovação da gestão/ administrativa & Fernandes et al. (2014), Yusr et al.(2014), Abrunhosa \& Sá (2008) \\
\hline Inovação tecnológica &
\end{tabular}

Quadro 4 - Componentes do desempenho inovador relacionados com a gestão da qualidade Fonte: Revisão de literatura (2016). 
Partindo desse levantamento foram definidas as duas primeiras hipóteses desse estudo:

H1: Práticas TQM Soft impactam positivamente na inovação por produtos;

H2: Práticas TQM Hard impactam positivamente na inovação por processos.

\section{GESTÃO DA QUALIDADE TOTAL (TQM) E ESTRATÉGIA COMPETITIVA}

A qualidade pode ser compreendida como um reflexo da estratégia competitiva adotada pelas empresas, ou desempenho estratégico organizacional. Tem sido tratada como fonte de vantagem competitiva, passando por um processo de evolução, de um enfoque operacional para um enfoque estratégico, onde estudiosos defendem que a qualidade deve ser incluída como um objetivo estratégico da firma (Prajogo, 2007).

Embora haja argumentos a favor da importância da gestão da qualidade para a competitividade das empresas, um número muito restrito de pesquisas tem se dedicado a investigar a relação entre qualidade e estratégia competitiva, a fim de proporcionar uma melhor compreensão conceitual e empírica (Prajogo, 2007; Belohlav, 1993).

Para autores como Reed et al.(1996), o conteúdo da TQM segue duas principais orientações: orientação para o cliente e orientação para o processo. A orientação para o cliente se refere ao esforço de superar os concorrentes na conquista de clientes por meio da oferta de produtos diferenciados.

Reed et al.(1996) defende que a orientação para o cliente da TQM está associada a uma estratégia de diferenciação, apesar disso não ser dito de forma explícita pela norma.Philips et al. (1983) argumenta que a qualidade pode ser situada e destacada entre as diferentes fontes de diferenciação, e que é uma abordagem que pode caracterizar uma estratégia de diferenciação, pois gera uma vantagem competitiva pela conquista da lealdade do cliente e redução de sua sensibilidade ao preço.

Esses autores, incluindo Prajogo (2007), Prajogo \& Sohal (2006), seguem a visão porteriana de que a qualidade é considerada base primária para a estratégia de diferenciação, onde as empresas se posicionam com base em determinados atributos que irão levar a um preço premium. A qualidade é um ponto de diferenciação que separa ou isola determinada empresa em termos de rivalidade competitiva, protegendo-a de forças que possam reduzir sua rentabilidade (Prajogo, 2007).

A estratégia de diferenciação indica que a empresa tende a dar forte ênfase na pesquisa $e$ desenvolvimento, de se arriscar em novos mercados, dando maior atenção a novos produtos e serviços (Gobeli \& Brown, 1994). Nesse sentido, para Miller
(1986), essa estratégia poderia suportar uma relação significativa com qualidade do produto, pois como o design, estilo ou inovação tecnológica, a qualidade pode ser considerada um aspecto de diferenciação.

A orientação para o processo diz respeito ao esforço das empresas em dar maior eficiência aos seus processos, na erradicação de defeitos e desperdícios. Sob a perspectiva do processo, Reed et al.(1996) sugere que a TQM gera vantagens competitivas relativas ao custo, que por sua vez reflete uma estratégia de liderança de custo.

Dentro da perspectiva porteriana, duas linhas de argumentação podem ser encontradas na relação dessa estratégia com a qualidade: a primeira, de que alta qualidade e baixo custo são incompatíveis, e a segunda, de que a melhoria da qualidade poderá resultar na redução dos custos de fabricação, após a empresa alcançar os benefícios de economia de escala (Philips et al., 1983).

Essa segunda argumentação tem sido fortalecida por estudos empíricos que têm demonstrado que o desempenho de qualidade possui um impacto favorável sobre a redução de custos, assim como na performance da empresa em termos de participação de mercado, volume de vendas e retorno sobre investimento (Prajogo, 2007).

Gobeli e Brown (1994) sugerem que a TQM está mais associada a uma liderança de valor, do que a uma liderança de custos, por dar uma maior ênfase na inovação do processo, do que na inovação do produto. Foca na produção de itens de qualidade a um preço competitivo, onde o valor do preço estará à altura do esforço da qualidade obtida.

Esses autores estão se referindo a perspectiva porteriana, de que as atividades interdependentes e coordenadas da firma, e seu desempenho, são a base de criação de valor para a organização (Toledo \& Bandeira-de-Mello, 2013).

Pesquisas como as de Belohlav (1993), Prajogo \& Sohal (2001), Prajogo \& Sohal (2006), e Prajogo (2007) defendem que não se pode conceber uma conclusão de exclusividade de associação da TQM com determinadas estratégias competitivas. A TQM poderá ser aplicada em contextos estratégicos distintos, como liderança de custo e diferenciação, pois a geração de um elevado nível de qualidade cria potencial e força para abranger ambas as estratégias.

Apesar disso, esses mesmos autores e outros não encontraram plena concordância dos resultados empíricos sobre a relação entre a TQM e as estratégias competitivas.

Prajogo \& Sohal(2006) e Prajogo (2007), por exemplo, constataram uma ligação entre TQM e estratégia de diferenciação, mas não com a estratégia de liderança em custos. Zatzick, Moliterno \& Fang (2012) identificaram que, para organizações com alta liderança em custo, a relação entre gestão da qualidade e performance organizacional foi positiva, e negativa 
para aquelas com baixa liderança em custo. No contexto da rede hoteleira, Pereira-Moliner et al. (2016) encontraram que as práticas de gestão da qualidade contribuem para ambas as estratégias, de liderança em custo e diferenciação.

Os resultados são inconclusivos, havendo evidências que sugerem que por meio da melhoria dos processos, as práticas de TQM contribuem para a redução de custos, e por meio da melhoria dos serviços e imagem organizacional, podem gerar maior diferenciação (Pereira-Moliner et al., 2012).

Dessa discussão foram elaboradas as seguintes hipóteses desse estudo, primeiramente averiguando a relação entre estratégia competitiva e desempenho organizacional (inovador), como feito no estudo de Zatzick, Moliterno \& Fang (2012):

H3: A Estratégia de diferenciação exerce maior influência sobre a inovação por produtos;

H4: A Estratégia de Liderança em custos exerce maior influência sobre a inovação por processos;

Em seguida, foram definidas as hipóteses para investigar a relação entre as estratégias competitivas e as práticas de TQM:

H5: A Estratégia de liderança em custos exerce maior influência para a adoção de Práticas de TQM Hard;

H6: A Estratégia de Diferenciação exerce maior influência para a adoção de Práticas de TQM Soft.

$\mathrm{Na}$ seção a seguir, serão apresentados os procedimentos metodológicos adotados neste estudo, a amostra de empresas e sujeitos pesquisados, e os métodos para análise dos dados coletados.

\section{METODOLOGIA}

O estudo é de natureza quantitativa e de finalidade descritiva, pretendendo descrever as relações entre os constructos práticas de gestão da qualidade, estratégias competitivas e desempenho inovador, no contexto de organizações industriais brasileiras.

Quanto aos procedimentos técnicos de pesquisa, foi realizada pesquisa bibliográfica e documental, que abrangeu artigos de periódicos nacionais e internacionais que abordassem a temática, dos últimos 12 anos, considerando o corpo restrito de pesquisa. O levantamento foi realizado por meio do Google Acadêmico, Portal Periódicos Capes e Scopus. Foi aplicada ainda a pesquisa de campo, por meio da técnica da survey ou levantamento, com envio de questionário eletrônico por e-mail.

A partir da pesquisa bibliográfica e documental foram definidas as dimensões do questionário, em anexo, dividido em cinco blocos: Práticas Soft de Gestão da Qualidade, Práticas Hard de Gestão da Qualidade, Estratégias Competitivas, Desempenho inovador, e Características gerais sobre a organização.

As questões definidas para os quatro primeiros blocos foram retiradas de instrumentos trabalhados por outros autores, como sintetizado no quadro 4 , a seguir.

\begin{tabular}{|c|c|c|}
\hline $\begin{array}{c}\text { BLOCOS DO } \\
\text { QUESTIONÁRIO }\end{array}$ & DIMENSÕES & AUTORES \\
\hline \multirow{5}{*}{$\begin{array}{l}\text { Práticas TQM Soft } \\
\text { (11 questões) }\end{array}$} & Planejamento Estratégico & Sadikoglu \& Olcay (2014) \\
\hline & $\begin{array}{l}\text { Comprometimento da Alta } \\
\text { Administração }\end{array}$ & $\begin{array}{c}\text { Talibet al. (2013); Sadikoglu } \\
\text { \& Olcay (2014) }\end{array}$ \\
\hline & Gestão do Conhecimento & Sadikoglu \& Olcay (2014) \\
\hline & Treinamento & $\begin{array}{c}\text { Conca, Llopis, \&Tarí, } \\
\text { (2004); Sadikoglu \& Olcay } \\
(2014)\end{array}$ \\
\hline & Gestão dos Empregados & Sadikoglu \& Zehir (2010) \\
\hline \multirow{5}{*}{$\begin{array}{l}\text { Práticas TQM Hard } \\
\text { (12 questões) }\end{array}$} & Gestão de Processos & $\begin{array}{l}\text { Sadikoglu \& Olcay (2014); } \\
\text { Conca et al. (2004) }\end{array}$ \\
\hline & Benchmarking & Talib et al. (2013) \\
\hline & Gestão da qualidade do fornecedor & Sadikoglu \& Olcay (2014) \\
\hline & Design de Produto e Serviço & Talib et al. (2013) \\
\hline & Foco no Cliente & Sadikoglu \& Olcay (2014) \\
\hline \multirow{2}{*}{$\begin{array}{l}\text { Estratégias Competitivas } \\
\text { (6 questões) }\end{array}$} & Liderança em custo & Pereira-Moliner et al. (2016) \\
\hline & Diferenciação & Pereira-Moliner et al. (2016) \\
\hline \multirow{2}{*}{$\begin{array}{c}\text { Desempenho inovador } \\
\text { (6 questões) }\end{array}$} & Inovação por Processo & Hung et al. (2011) \\
\hline & Inovação por Produto & Silva et al. (2014) \\
\hline
\end{tabular}

Quadro 5 - Estrutura do Questionário e suas dimensões Fonte: Revisão da Literatura (2016). 
No bloco, características gerais da organização (12 questões),foram definidas informações sobre a função do respondente, setor de atuação da empresa, e tamanho. Foram definidas ainda as variáveis de controle aplicadas na análise estatística: grau de internacionalização (quanto ao percentual de vendas internacional e de número de países para os quais exporta), adoção da certificação ISO 9001 (2000, 2008 e 2015), existência de departamento de pesquisa e desenvolvimento, adoção de um modelo de gestão de inovação padronizado, e grau em que a estrutura organizacional da empresa é orientada para projetos.

O tamanho da firma foi determinado com uso da classificação do porte das empresas do Instituto Brasileiro de Geografia e Estatística [IBGE], com base no número de empregados do estabelecimento.

Para viabilizar a aplicação do questionário por e-mail, foi realizado o levantamento dos contatos das empresas por meio:1) do Catálogo dos Exportadores Brasileiros da Confederação Nacional da Indústria, disponível no site www.brazil4export.com, onde a busca focou somente empresas do setor industrial, e com faixa de exportação acima de 1 milhão; 2) do Portal "Datamaq" da Associação Brasileira de Indústria de Máquinas e Equipamentos, disponível no site www.datamaq.org.br; 3) do contato com a Associação Brasileira dos Fabricantes de Brinquedos, cujo responsável contribuiu enviando o questionário da pesquisa para seus associados; 4) do contato com responsável do Inmetro, que concedeu listagem das empresas com certificação ISO 9001, e seus respectivos contatos; 5) do contato com a Sra. Marta Campelo, da Unidade de Acesso a Mercados, do Sebrae-Ceará, que nos concedeu a lista de contatos de empresas exportadoras cearenses; 6) do acesso à lista de empresas exportadoras no site da Associação de Empresas de Equipamentos Elétricos e Eletrônicos.

$\mathrm{O}$ envio dos e-mails foi realizado no período de 04 a 28 de julho de 2016, obtendo-se um retorno de
65 empresas até a data final. Foi encaminhado o questionário, dando-se prioridade às empresas do setor da indústria de transformação, exportadoras e certificadas pela ISO 9001. Também foram consideradas para amostra empresas não exportadoras e/ou não certificadas pela ISO 9001, para fins de confrontação.

Os respondentes da pesquisa foram 34 gestores executivos, 23 gestores intermediários e 8 supervisores/líder de equipe.

Da lista de contatos apresentada no portal Datamaq, foram enviados e-mails para as empresas de máquinas e equipamentos que servem aos setores alimentício, agricultura, geração de energia, máquinasferramenta, saneamento básico e ambiental, bem como aos setores transversais: bombas, moto bombas e acessórios; hidráulica, pneumática e automação; e refrigeração industrial. Da planilha de contatos obtida com o Inmetro foi enviado e-mail para todas as empresas do setor de eletroeletrônicos, e máquinas e equipamentos.

Em seguida a esse levantamento, foi aplicada a técnica de análise de regressão múltipla, com uso do método stepwise para análise dos dados coletados, e teste das hipóteses de pesquisa.

\section{RESULTADOS DA PESQUISA}

\subsection{Caracterização da Amostra}

A amostra da pesquisa consistiu em 65organizações da indústria de transformação, conforme tabela a seguir, sendo $64,6 \%$ do Sudeste, $21,5 \%$ do Sul, $12,3 \%$ do Nordeste, e uma empresa do Norte. Destas organizações, $40 \%$ são empresas de pequeno porte, $33,8 \%$ de médio porte, e $26,2 \%$ de grande porte.

Tabela 1 - $\mathrm{N}^{\mathrm{o}}$ de Empresas por Setor de Atuação

\begin{tabular}{|l|c|c|}
\hline \multicolumn{1}{|c|}{ Setores de Atuação } & $\begin{array}{c}\mathbf{N}^{\mathbf{0}} \\
\text { Empresas }\end{array}$ & Percentual \\
\hline Indústria de Produtos Alimentícios & 6 & 9,2 \\
\hline Indústria Química & 1 & 1,5 \\
\hline Peças Automotivas & 1 & 1,5 \\
\hline Indústria de calçados & 2 & 3,1 \\
\hline Indústria de Brinquedos & 10 & 15,4 \\
\hline Caldeiraria & 1 & 1,5 \\
\hline Utensílios domésticos & 1 & 1,5 \\
\hline Indústria Têxtil & 4 & 6,2 \\
\hline Confecção de artigos de vestuário e acessórios & 5 & 7,7 \\
\hline Cosméticos, Perfumaria e Higiene & 2 & 3,1 \\
\hline Elétrica e Eletrônica & 18 & 27,7 \\
\hline Máquinas e equipamentos & 13 & 20 \\
\hline Aeroespacial & 1 & 1,5 \\
\hline Total & 65 & 100,0 \\
\hline
\end{tabular}

Fonte: Resultados da Pesquisa (2016) 
Quanto às variáveis de controle que foram aplicadas na análise estatística, e que também caracterizam as empresas pesquisadas, evidenciou-se que que $50,8 \%$ das empresas são certificadas pela ISO 9001:2008, 4,6\% pela ISO 9001:2000 e 6,2\% pela ISO 9001:2015. Demais 38,5\% não possuem certificação.

Quanto ao grau de internacionalização, 72,2\% das empresas são exportadoras, contra $27,7 \%$ que não realiza vendas internacionais.

Das empresas que exportam, $52,3 \%$ apresentaram percentual de vendas internacionais menor que $20 \%, 9,2 \%$ entre $20 \%$ a $30 \%, 4,6 \%$ entre $31 \%$ a $50 \%$, outros $4,6 \%$ entre $51 \%$ a $60 \%$, e uma empresa, acima de $70 \%$. Com relação ao número de países para os quais exporta, $47,7 \%$ das empresas comercializam de 1 a 5 países, $12,3 \%$ de 6 a 10 países, $6,2 \%$ acima de 40 países, $3,1 \%$ de 21 a 30 países, uma empresa, de 11 a 15 países, e outra, de 31 a 40 países.
Quanto à existência de um departamento de Pesquisa e Desenvolvimento na organização, 56,9\% das empresas pesquisadas afirmou que possuem centros de P\&D.

Destacou-se ainda que 44,6\% das empresas adotam um modelo padronizado de gestão da inovação, contra $55,4 \%$ que não adotam.

\subsection{Análise Descritiva das Dimensões do Estudo}

$\mathrm{Na}$ análise descritiva das práticas de gestão da qualidade, as empresas foram analisadas segundo o porte, para fins de enriquecimento do estudo. Os resultados das tabelas revelam que quanto maior o porte da empresa, maiores as médias de adoção de práticas de qualidade.

Tabela 2 - Adoção de Práticas TQM Soft - Média Geral e Por Porte da Empresa

\begin{tabular}{|c|c|c|c|c|}
\hline \multirow{2}{*}{ Categorias } & Pequeno Porte & Médio Porte & Grande Porte & Média Geral \\
\cline { 2 - 5 } & Média & Média & Média & \\
\hline Planejamento Estratégico & 5,65 & 6,13 & 6,52 & 6,05 \\
\hline $\begin{array}{c}\text { Comprometimento da Alta } \\
\text { Administração }\end{array}$ & 5,58 & 5,96 & 6,18 & 5,86 \\
\hline Gestão do Conhecimento & 4,36 & 5,36 & 6,00 & 5,13 \\
\hline Treinamento & 4,72 & 5,47 & 5,54 & 5,19 \\
\hline Gestão dos Empregados & 4,69 & 5,03 & 5,71 & 5,07 \\
\hline Média Geral TQM Soft & 5,00 & 5,59 & 5,99 & 5,45 \\
\hline
\end{tabular}

Fonte: Resultados da pesquisa (2016)

Tabela 3 - Adoção de Práticas TQM Hard - Média Geral e Por Porte da Empresa

\begin{tabular}{|c|c|c|c|c|}
\hline \multirow{2}{*}{ Categorias } & Pequeno Porte & Médio Porte & Grande Porte & Média Geral \\
\cline { 2 - 5 } & Média & Média & Média & \\
\hline Gestão de Processos & 4,33 & 4,80 & 4,96 & 4,66 \\
\hline Benchmarking & 3,76 & 4,40 & 4,94 & 4,29 \\
\hline $\begin{array}{c}\text { Gestão da Qualidade do } \\
\text { Fornecedor }\end{array}$ & 4,38 & 5,02 & 4,91 & 4,74 \\
\hline Design Produto/Serviço & 5,45 & 5,45 & 5,86 & 5,55 \\
\hline Foco no Cliente & 5,23 & 5,48 & 5,88 & 5,48 \\
\hline Média Geral TQM Hard & 4,63 & 5,03 & 5,31 & 4,95 \\
\hline
\end{tabular}

Fonte: Resultados da pesquisa (2016)

Quanto às dimensões de orientação estratégica, para a amostra total, a maior média foi para a estratégia de liderança em custos $(5,51)$, seguida pela estratégia de diferenciação $(5,32)$. Com relação à inovação, predominou na amostra pesquisada uma maior aplicação da inovação por produtos $(5,32)$, do que da inovação por processos $(4,79)$.

\subsection{Influência das Práticas de TQM sobre a Inovação}

Para testar as hipóteses desta pesquisa, aplicou-se a análise de regressão múltipla, por meio do método stepwise. Entre as variáveis, práticas de TQM Hard e práticas de TQM Soft, foi observado um coeficiente de correlação de Pearson acima de 0,8, o que fez com que fossem aplicadas separadamente na análise de regressão. Não foi possível incluir o porte da empresa como elemento de análise, pois seu 
levantamento junto às empresas foi efetuado na forma de variável categórica, e não quantitativa.

\subsubsection{Inovação por Produto}

Como primeira etapa de análise, aplicou-se a análise de regressão para testar as hipóteses01 e 03 da pesquisa:

H1: Práticas TQM Soft impactam positivamente na inovação por produtos; H3: A Estratégia de diferenciação exerce maior influência sobre a inovação por produtos.

Considerou-se como variável dependente a inovação por produto, e como variáveis independentes: Práticas TQM Hard, Estratégia de Diferenciação, Estratégia de Liderança em Custo, Grau de orientação para projetos. Como variáveis dummy, foram inclusos, Pesquisa e Desenvolvimento (se possui ou não um departamento), Modelo de gestão de inovação padronizado (se adota ou não), Certificação ISO 9001 (se adota ou não), Internacionalização (se exporta ou não).

Os resultados gerados revelaram elevada correlação entre a variável Práticas de TQM Hard e as variáveis "Grau de orientação para projetos" e "Estratégia de diferenciação", com valor de coeficiente de pearson positivo, maior que 0,7. Rodou-se novamente o primeiro modelo de regressão, sem essas duas últimas variáveis.

$O$ primeiro modelo de regressão gerado apresentou a variável "Práticas de TQM Hard" como o preditor significante de maior impacto sobre a variável dependente "Inovação por produto", com capacidade de explicar $49,7 \%$ da variação desta, com significância de $1 \%$.

O segundo modelo de regressão gerado, revelou que a "Estratégia de Liderança em Custos" também se constitui numa preditora significativa da Inovação por Produto, a nível de 5\%, e sua inclusão aumenta o poder explicativo do modelo para $53,6 \%$. Verificando-se o valor da estatística de Durbin-watson, próximo de 2, constata-se que a hipótese de independência de erros é satisfeita, que é um dos pressupostos da regressão.

Foi testada a significância dos modelos por meio da análise de variância (ANOVA), constatando-se que ambos são significantes a nível de $1 \%$.

A tabela4 a seguir, mostra o grau em que cada parâmetro do modelo afeta a saída (inovação por produto) e sua significância. Verifica-se que todos os parâmetros são significantes, destacando-se as "práticas hard" no segundo modelo de regressão, como o parâmetro que gera maior impacto na inovação por produto.

Tabela 4 - Coeficientes dos modelos de Regressão - Inovação por Produto - Teste 1

\begin{tabular}{|c|c|c|c|c|c|c|c|c|}
\hline \multirow{2}{*}{\multicolumn{2}{|c|}{ Modelos }} & \multicolumn{2}{|c|}{$\begin{array}{l}\text { Coeficientes Não } \\
\text { Padronizados } \\
\end{array}$} & \multirow{2}{*}{$\begin{array}{c}\begin{array}{c}\text { Coeficientes } \\
\text { Padronizados }\end{array} \\
\text { Beta } \\
\end{array}$} & \multirow[t]{2}{*}{$\mathbf{t}$} & \multirow[t]{2}{*}{ Sig. } & \multicolumn{2}{|c|}{$\begin{array}{l}\text { Estatísticas de } \\
\text { Colinearidade }\end{array}$} \\
\hline & & B & Erro Padrão & & & & Tolerância & VIF \\
\hline \multirow{2}{*}{1} & (Constant) & 1,001 &, 562 & & 1,782 & ,080 & & \\
\hline & Práticas TQM Hard & 872 &, 110 & ,705 & 7,895 & ,000 & 1,000 & 1,000 \\
\hline \multirow{3}{*}{2} & (Constant) &, 565 &, 578 & & ,978 & 332 & & \\
\hline & Práticas TQM Hard & ,638 & ,149 & 516 & 4,281 &, 000 &, 516 & 1,938 \\
\hline & $\begin{array}{l}\text { Estratégia Liderança } \\
\text { em Custo }\end{array}$ & 289 & , 128 & ,272 & 2,259 & ,027 &, 516 & 1,938 \\
\hline
\end{tabular}

Fonte: Resultados da Pesquisa (2016).

Foi avaliada a hipótese de nãomulticolineariedade, que foi satisfeita, com valores de VIF menores que 10 e tolerâncias todas acima de 0,20 (FIELD, 2009). Analisando-se o histograma e o gráfico dos resíduos padronizados versus os valores preditos, constatou-se normalidade dos resíduos e não heterocedasticidade.

Aplicando-se a mesma análise acima para as práticas de TQM Soft, os modelos de regressão múltipla gerados apresentaram problemas relativos à normalidade de resíduos e heterocedasticidade, não sendo possível verificar uma relação da variável com a dimensão de inovação por produto.
Logo, a primeira hipótese do estudo "Práticas TQM Soft impactam positivamente na inovação por produtos" foi refutada.

Ainda considerando a inovação por produto como variável dependente, foi aplicada a mesma análise acima, dessa vez, desconsiderando a variável "Práticas de TQM Hard", e incluindo-se as variáveis "estratégia de diferenciação" e "grau de orientação para projetos" para analisar sua influência sobre a variável dependente.

O primeiro modelo de regressão gerado apresenta a variável "estratégia de diferenciação" como um preditor mais significativo da inovação por produto, com capacidade de explicar $63,2 \%$ de sua variação, a nível de $1 \%$. O segundo modelo de 
regressão gerado inclui a variável "pesquisa e desenvolvimento", que apresentou menor impacto sobre a inovação por produto, explicando $2,6 \%$ de sua variação.

A hipótese de independência de erros foi satisfeita, pois o valor da estatística de Durbin-watson foi próximo de 2. A análise de variância (ANOVA), constatando-se a significância dos modelos a nível de $1 \%$.

A tabela 5 a seguir, mostra o grau em que cada parâmetro do modelo afeta a saída (inovação por produto) e sua significância. Nestas regressões também foram satisfeitas as hipóteses de nãomulticolineariedade, bem como da normalidade dos resíduos e da não heterocedasticidade.

Tabela 5 - Coeficientes dos modelos de Regressão - Inovação por Produto - Teste 2

\begin{tabular}{|c|c|c|c|c|c|c|c|c|}
\hline & \multirow{2}{*}{ Modelos } & \multicolumn{2}{|c|}{$\begin{array}{c}\text { Coeficientes Não } \\
\text { Padronizados }\end{array}$} & \multirow{2}{*}{$\begin{array}{c}\begin{array}{c}\text { Coeficientes } \\
\text { Padronizados }\end{array} \\
\text { Beta }\end{array}$} & \multirow{2}{*}{$\mathbf{t}$} & \multirow{2}{*}{ Sig. } & \multicolumn{2}{|c|}{$\begin{array}{l}\text { Estatísticas de } \\
\text { Colinearidade }\end{array}$} \\
\hline & & $\mathbf{R}$ & Frro Padrão & & & & Tolerânci & VIF \\
\hline \multirow{2}{*}{1} & (Constant) & 360 & ,497 & & ,724 & ,472 & & \\
\hline & Estratégia de Diferenciação & ,941 & ,091 & ,795 & 10,321 & ,000 & 1,000 & 1,000 \\
\hline \multirow{3}{*}{2} & (Constant) & ,366 & ,483 & &, 758 & 451 & & \\
\hline & Estratégia de Diferenciação & ,887 & ,092 & ,750 & 9,657 & 000 & ,928 & 1,077 \\
\hline & $\begin{array}{l}\text { Pesquisa e } \\
\text { Desenvolvimento }\end{array}$ & ,480 & ,221 &, 169 & 2,171 & ,034 & ,928 & 1,077 \\
\hline
\end{tabular}

Fonte: Resultados da Pesquisa (2016).

Comparando-se os resultados das tabelas $4 \mathrm{e}$ 5, confirma-se a terceira hipótese da pesquisa, de que "A Estratégia de diferenciação exerce maior influência sobre a inovação por produtos", pois a estratégia de diferenciação foi o parâmetro de maior impacto.

\subsubsection{Inovação por processos}

Como segunda etapa de análise, foi realizado o teste da hipótese 02 da pesquisa "Práticas TQM hard impactam positivamente na inovação por processos" e da hipótese 04 "A Estratégia de Liderança em custos exerce maior influência sobre a inovação por processos".

Considerou-se como variável dependente a inovação por processos, e como variáveis independentes: Práticas TQM Hard, Estratégia de Liderança em Custo. Como variáveis dummy, foram inclusos, Pesquisa e Desenvolvimento (se possui ou não um departamento), Modelo de gestão de inovação padronizado (se adota ou não), Certificação ISO 9001 (se adota ou não), Internacionalização (se exporta ou não).

Não foram incluídas as variáveis Estratégia de Diferenciação e Grau de orientação para projetos por conta da alta correlação com a variável Práticas TQM
Hard, acima de 0,7. Sendo rodada a regressão, os modelos gerados não foram satisfatórios, por conta de problema de heterocedasticidade. Por conta disso, foi retirada a variável "Liderança em custos", que possui uma correlação moderada com "Práticas de TQM Hard", muito próximo de 0,7 .

Aplicando-se novamente a regressão, foi resolvido o problema de heterocedasticidade, e o primeiro modelo de regressão gerado destacou a variável "Práticas de TQM Hard" como uma preditora significante e que apresenta um maior poder explicativo da inovação por processos, explicando $50,7 \%$ de sua variação, a nível de $1 \%$. O segundo modelo de regressão gerado inclui a variável "modelo de gestão de inovação padronizado", significante a nível de $1 \%$, que aumenta o poder explicativo do modelo para $55,8 \%$.

O valor da estatística de Durbin-watsonfoi próximo de 2, satisfazendo a hipótese de independência de erros. A análise de variância (ANOVA) atestoua significância dos modelos a nível de $1 \%$.

A tabela 6 a seguir, mostra o grau em que cada parâmetro do modelo afeta a saída (inovação por processo) e sua significância. $\mathrm{O}$ valor de Beta demonstra que a variável "Práticas de TQM Hard" tem maior impacto sobre a inovação por processo. 
Práticas de Gestão da Qualidade, Estratégias Competitivas e Desempenho Inovador na Indústria de Transformação Brasileira

Tabela 6 - Coeficientes dos modelos de Regressão - Inovação por Processo - Teste 1

\begin{tabular}{|c|c|c|c|c|c|c|c|c|}
\hline \multirow{2}{*}{\multicolumn{2}{|c|}{ Modelos }} & \multicolumn{2}{|c|}{$\begin{array}{c}\text { Coeficientes Não } \\
\text { Padronizados }\end{array}$} & \multirow{2}{*}{$\begin{array}{c}\begin{array}{c}\text { Coeficientes } \\
\text { Padronizados }\end{array} \\
\text { Beta }\end{array}$} & \multirow[t]{2}{*}{$\mathbf{t}$} & \multirow[t]{2}{*}{ Sig. } & \multicolumn{2}{|c|}{$\begin{array}{l}\text { Estatísticas de } \\
\text { Colinearidade }\end{array}$} \\
\hline & & B & Erro Padrão & & & & Tolerância & VIF \\
\hline \multirow{2}{*}{1} & (Constant) & 0,671 & 0,526 & & 1,277 & 206 & & \\
\hline & Práticas TQM Hard & 0,833 & 0,103 & 0,712 & 8,056 & 000 & 1,000 & 1,000 \\
\hline \multirow{3}{*}{2} & (Constant) & 0,917 & 0,510 & & 1,797 & 077 & & \\
\hline & Práticas TQM Hard & 0,722 & 0,107 & 0,618 & 6,749 &, 000 & 850 & 1,176 \\
\hline & $\begin{array}{l}\text { Modelo de gestão de } \\
\text { inovação padronizado }\end{array}$ & 0,678 & 0,253 & 0,245 & 2,677 & ,010 & ,850 & 1,176 \\
\hline
\end{tabular}

Fonte: Resultados da Pesquisa (2016).

Nestes modelos, as hipóteses de nãomulticolineariedade, da normalidade dos resíduos e da não heterocedasticidade foram satisfeitas.

Aplicando-se a mesma análise acima para as práticas de TQM Soft, os modelos de regressão múltipla gerados apresentaram problemas relativos à normalidade de resíduos, não sendo possível verificar uma relação da variável com a dimensão de inovação por processos.

Foi confirmada, portanto, a segunda hipótese da pesquisa, de que as práticas de TQM Hard afetam positivamente a inovação por processos.

Prosseguindo na análise das variáveis que afetam a Inovação por processo, foi realizado um segundo teste, com foco nas variáveis "estratégia de diferenciação" e "estratégia de liderança em custos". Para tanto, foi retirada da análise de regressão a variável "práticas de TQM Hard", que apresenta correlação forte e moderada com essas variáveis, respectivamente. Foram mantidas todas as variáveis dummy explicitadas no início dessa seção.

Como resultado, foram obtidos três modelos de regressão, todos significantes a nível de $1 \%$, e com valor de Durbin-Watson, próximo de 2, satisfazendo a hipótese de independência de erros. O primeiro modelo de regressão demonstra que a Estratégia de diferenciação, sozinha, explica $52,2 \%$ da variação da inovação por processos.

O segundo modelo inclui, além da estratégia de diferenciação, a variável "modelo de inovação padronizado", que aumenta o poder explicativo da regressão para $61,7 \%$. O terceiro modelo, além dessas duas variáveis, inclui a variável "estratégia de liderança em custos", que eleva o poder explicativo da regressão para 64,6\%. A análise de variância (ANOVA) demonstrou que todos os modelos são significantes a nível de $1 \%$.

A tabela 7 a seguir, demonstra o peso dos parâmetros de cada modelo, revelando que a estratégia de diferenciação apresenta um maior impacto sobre a inovação por processos, do que a estratégia de liderança em custos, confirmando a quarta hipótese da pesquisa.

A variável "modelo de inovação padronizado" é o parâmetro com menor peso sobre inovação por processos.

Tabela 7 - Coeficientes dos modelos de Regressão - Inovação por Processo - Teste 2

\begin{tabular}{|c|c|c|c|c|c|c|c|c|}
\hline \multirow{2}{*}{\multicolumn{2}{|c|}{ Modelos }} & \multicolumn{2}{|c|}{$\begin{array}{c}\text { Coeficientes Não } \\
\text { Padronizados }\end{array}$} & \multirow{2}{*}{$\begin{array}{c}\begin{array}{c}\text { Coeficientes } \\
\text { Padronizados }\end{array} \\
\text { Beta }\end{array}$} & \multirow[t]{2}{*}{$\mathbf{t}$} & \multirow{2}{*}{ Sig. } & \multicolumn{2}{|c|}{$\begin{array}{l}\text { Estatísticas de } \\
\text { Colinearidade }\end{array}$} \\
\hline & & B & Erro Padrão & & & & Tolerância & VIF \\
\hline \multirow{2}{*}{1} & (Constante) & ,639 &, 525 & & 1,218 & 228 & & \\
\hline & Estratégia de diferenciação & ,791 &, 096 &, 722 & 8,221 &, 000 & 1,000 & 1,000 \\
\hline \multirow{3}{*}{2} & (Constante) & ,718 & ,474 & & 1,515 &, 135 & & \\
\hline & Estratégia de diferenciação & ,705 & ,090 & ,644 & 7,878 &, 000 & ,940 & 1,064 \\
\hline & $\begin{array}{l}\text { Modelo de gestão de } \\
\text { inovação padronizado }\end{array}$ & ,835 & 214 & ,319 & 3,905 & ,000 & ,940 & 1,064 \\
\hline \multirow{3}{*}{3} & (Constante) & ,275 & ,475 & & ,579 & ,565 & & \\
\hline & Estratégia de diferenciação & ,486 &, 114 & ,444 & 4,250 &, 000 &, 515 & 1,941 \\
\hline & $\begin{array}{l}\text { Modelo de gestão de } \\
\text { inovação padronizado }\end{array}$ & ,718 & ,206 &, 274 & 3,478 & ,001 & ,903 & 1,108 \\
\hline & $\begin{array}{l}\text { Estratégia de liderança em } \\
\text { custos }\end{array}$ & ,299 & ,105 & ,303 & 2,847 & ,006 & ,496 & 2,017 \\
\hline
\end{tabular}

Fonte: Resultados da Pesquisa (2016). 


\subsection{Influência das Estratégias Competitivas sobre as Práticas de TQM}

\subsubsection{Práticas de TQM Hard}

Nesta seção foi analisada a influência das estratégias competitivas sobre as práticas TQM Hard. Aplicou-se a análise de regressão, com uso do método stepwise, para testar a quinta hipótese de pesquisa: "A Estratégia de liderança em custos exerce maior influência para a adoção de Práticas de TQM Hard".

Considerou-se como variável dependente Práticas de TQM Hard, e como variáveis independentes: Estratégia de Diferenciação, Estratégia de Liderança em Custo, Grau de orientação para projetos. Como variáveis dummy, foram inclusos, Pesquisa e Desenvolvimento (se possui ou não um departamento), Modelo de gestão de inovação padronizado (se adota ou não), Certificação ISO 9001 (se adota ou não), Internacionalização (se exporta ou não).
Foram gerados três modelos de regressão, com uso do método de stepwise. O primeiro modelo apresenta a estratégia de diferenciação, que sozinha, explica 59,7\% da variação das práticas de TQM Hard. No segundo modelo, acrescenta-se a estratégia de liderança em custos, que explica somente $4,6 \%$ da variação das práticas de TQM Hard.

No terceiro modelo, é acrescentada a variável "pesquisa e desenvolvimento", que apresentou capacidade de explicação de 4,3\%.Foi satisfeita a hipótese de independência de erros por meio do teste de Durbin-Watson. A análise de variância (ANOVA) demonstrou que todos os modelos são significantes a nível de $1 \%$.

Verifica-se por meio da tabela 8 , que a estratégia de diferenciação é o parâmetro com maior peso sobre as práticas de TQM Hard, em termos de valor de Beta, para todos os modelos de regressão, o que refuta a quinta hipótese do estudo.

Tabela 8 - Coeficientes dos modelos de Regressão - Práticas de TQM Hard

\begin{tabular}{|c|c|c|c|c|c|c|c|c|}
\hline \multirow{2}{*}{\multicolumn{2}{|c|}{ Modelos }} & \multicolumn{2}{|c|}{$\begin{array}{l}\text { Coeficientes Não } \\
\text { Padronizados }\end{array}$} & \multirow{2}{*}{$\begin{array}{c}\begin{array}{c}\text { Coeficientes } \\
\text { Padronizados }\end{array} \\
\text { Beta } \\
\end{array}$} & \multirow[t]{2}{*}{$\mathbf{t}$} & \multirow[t]{2}{*}{ Sig. } & \multicolumn{2}{|c|}{$\begin{array}{l}\text { Estatísticas de } \\
\text { Colinearidade }\end{array}$} \\
\hline & & B & Erro Padrão & & & & Tolerância & VIF \\
\hline \multirow{2}{*}{1} & (Constante) & ,903 &, 435 & & 2,078 & 042 & & \\
\hline & Estratégia de diferenciação & ,764 & ,080 & ,773 & 9,584 &, 000 & 1,000 & 1,000 \\
\hline \multirow{3}{*}{2} & (Constante) &, 519 & ,434 & & 1,195 & 237 & & \\
\hline & Estratégia de diferenciação & 559 &, 105 & ,565 & 5,307 &, 000 &, 516 & 1,938 \\
\hline & $\begin{array}{l}\text { Estratégia de Liderança em } \\
\text { Custos }\end{array}$ & 265 & ,095 & 298 & 2,801 & ,007 &, 516 & 1,938 \\
\hline \multirow{4}{*}{3} & (Constante) &, 519 &, 409 & & 1,269 & ,209 & & \\
\hline & Estratégia de diferenciação & 495 & ,101 & ,501 & 4,893 &, 000 & ,494 & 2,026 \\
\hline & $\begin{array}{l}\text { Estratégia de Liderança em } \\
\text { Custos }\end{array}$ & 271 & ,089 & 304 & 3,038 & ,004 & ,516 & 1,938 \\
\hline & Pesquisa e Desenvolvimento & ,531 & ,178 & ,223 & 2,989 & ,004 & ,928 & 1,078 \\
\hline
\end{tabular}

Fonte: Resultados da Pesquisa (2016).

\subsubsection{Práticas de TQM Soft}

Nesta seção foi analisada a influência das estratégias competitivas sobre as práticas TQM Soft, sendo testada a sexta hipótese do estudo: "A Estratégia de Diferenciação exerce maior influência para a adoção de Práticas de TQM Soft".

Para tanto aplicou-se a análise de regressão, considerando-se como variável dependente Práticas de TQM Soft, e como variáveis independentes: Estratégia de Diferenciação, Estratégia de Liderança em Custo, Grau de orientação para projetos. Como variáveis dummy, foram inclusos, Pesquisa e Desenvolvimento (se possui ou não um departamento), Modelo de gestão de inovação padronizado (se adota ou não),
Certificação ISO 9001 (se adota ou não), Internacionalização (se exporta ou não).

Com uso do método stepwise, foram gerados 4 modelos de regressão, significantes a nível de $1 \%$, segundo a análise de variância ANOVA. O primeiro modelo de regressão apresenta somente a variável "estratégia de diferenciação", que sozinha explica 52\% da variação das práticas de TQM Soft. No segundo modelo, é acrescentada a variável "certificação ISO 9001", que sozinha explica somente $6,5 \%$ da variação.

O terceiro modelo gerado adiciona a variável "estratégia de liderança em custos", que sozinho explica 4,6\% da variação das práticas de TQM Soft. Por fim, o quarto modelo adiciona a variável "pesquisa e desenvolvimento", que explica sozinho $2,9 \%$ da variação da saída da regressão. O teste de Durbin- 
Watson demonstrou que a hipótese de independência de erros foi satisfeita.

A tabela 9 apresenta os pesos dos parâmetros de cada modelo de regressão. Verifica-se que “estratégia de diferenciação" é o que apresenta maior peso sobre o resultado das práticas de TQM Soft, confirmando-se a sexta hipótese do estudo.

Tabela 9 - Coeficientes dos modelos de Regressão - Práticas de TQM Soft

\begin{tabular}{|c|c|c|c|c|c|c|c|c|}
\hline \multirow{2}{*}{\multicolumn{2}{|c|}{ Modelos }} & \multicolumn{2}{|c|}{$\begin{array}{l}\text { Coeficientes Não } \\
\text { Padronizados }\end{array}$} & \multirow{2}{*}{$\begin{array}{c}\begin{array}{c}\text { Coeficientes } \\
\text { Padronizado } \\
\text { s }\end{array} \\
\text { Beta }\end{array}$} & \multirow[t]{2}{*}{$\mathbf{t}$} & \multirow[t]{2}{*}{ Sig. } & \multicolumn{2}{|c|}{$\begin{array}{l}\text { Estatísticas de } \\
\text { Colinearidade }\end{array}$} \\
\hline & & B & Erro Padrão & & & & Tolerância & VIF \\
\hline \multirow{2}{*}{1} & (Constante) & 1,495 & ,496 & & 3,015 & ,004 & & \\
\hline & Estratégia de diferenciação &, 745 & ,091 & ,721 & 8,199 & ,000 & 1,000 & 1,000 \\
\hline \multirow{3}{*}{2} & (Constante) & 1,318 & ,468 & & 2,816 & ,007 & & \\
\hline & Estratégia de diferenciação & ,704 & ,086 & ,681 & 8,163 & ,000 & ,976 & 1,024 \\
\hline & Certificação ISO 9001 & ,650 & ,210 & ,258 & 3,091 &, 003 & ,976 & 1,024 \\
\hline \multirow{4}{*}{3} & (Constante) & ,923 & ,468 & & 1,972 &, 053 & & \\
\hline & Estratégia de diferenciação & ,491 & ,113 & ,475 & 4,336 & ,000 & ,513 & 1,951 \\
\hline & Certificação ISO 9001 & ,625 & 200 & ,248 & 3,128 &, 003 & ,974 & 1,026 \\
\hline & $\begin{array}{l}\text { Estratégia de Liderança em } \\
\text { Custos }\end{array}$ & ,278 &, 102 & ,299 & 2,739 &, 008 &, 515 & 1,941 \\
\hline \multirow[t]{5}{*}{4} & (Constante) & ,935 & ,435 & & 2,065 & ,043 & & \\
\hline & Estratégia de diferenciação & ,440 &, 112 & ,426 & 3,939 &, 000 & ,492 & 2,032 \\
\hline & Certificação ISO 9001 & ,571 & ,195 & ,227 & 2,926 & ,005 & ,959 & 1,043 \\
\hline & $\begin{array}{l}\text { Estratégia de Liderança em } \\
\text { Custos }\end{array}$ &, 284 & ,098 &, 305 & 2,888 &, 005 &, 515 & 1,943 \\
\hline & Pesquisa e Desenvolvimento &, 445 & ,197 & ,179 & 2,254 & ,028 & ,914 & 1,095 \\
\hline
\end{tabular}

Fonte: Resultados da Pesquisa (2016).

\section{DISCUSSÃO DOS RESULTADOS}

Os resultados da pesquisa demonstram que no contexto das empresas do ramo industrial brasileiro analisadas, as práticas de TQM Hard estão mais associadas ao aumento da inovação por processos, do que da inovação por produtos, apesar de impactar em ambas as dimensões de inovação.

Esse resultado corrobora com os achados da corrente acadêmica que, conforme Krivokapic et al. (2013), defende que os sistemas de gestão de qualidade e inovação são compatíveis, e de que as práticas de gestão da qualidade criam condições internas favoráveis à mudança, tornando as empresas mais abertas à inovação.

O impacto positivo da gestão da qualidade sobre a inovação, nesse sentido, advém quando as práticas de qualidade focam mais na melhoria do desempenho dos processos, do que em seu controle, ou seja, somente as empresas com uma abordagem eficaz de qualidade se tornarão mais predispostas a inovar (Krivokapicet al., 2013; Wright et al., 2012).

Não foi possível verificar a relação das Práticas de TQM Soft com a inovação por produtos e por processos.

Os resultados revelaram ainda que a orientação estratégica para a diferenciação tem maior relação com a inovação por produto e por processos, do que a orientação para liderança em custos.

$\mathrm{Na}$ relação entre orientação estratégica e práticas de TQM, identificou-se que a estratégia de diferenciação, exerce influência significativa tanto para a adoção de práticas de TQM Hard, quanto para a adoção de práticas de TQM Soft, com maior impacto sobre a adoção de práticas TQM Hard. Dentre as práticas de TQM Hard, as dimensões de maiores médias foram "Design do produto/serviço", "Foco no Cliente" e "Gestão da qualidade do fornecedor".

Desses resultados, pode-se depreender que as práticas de gestão da qualidade, em especial, as de TQM Hard, são utilizadas como fontes de diferenciação pelas empresas pesquisadas. Por meio delas, as empresas se posicionam para a obtenção de determinados atributos que contribuam para a superação da concorrência na conquista dos clientes, como observado por Philips et al. (1983), Miller (1986), Prajogo (2007), e Prajogo\&Sohal (2006).

Como achados complementares da pesquisa, verificou-se que as empresas que possuem um departamento de pesquisa e desenvolvimento são mais propensas a inovação por produtos. Dentre elas, se destacaram neste estudo, as empresas da indústria de brinquedos, elétrica e eletrônica, máquinas e equipamentos, têxtil, confecção e vestuário, indústria 
química, e as do setor de cosméticos, perfumaria e higiene.

Da amostra pesquisada, 37 empresas possuem um departamento de pesquisa e desenvolvimento, sendo em sua maioria, exportadoras $(72,9 \%)$. Esse grupo de empresas são mais orientadas para a estratégia de diferenciação (média 5,6), em comparação com as empresas que não possuem um departamento de pesquisa e desenvolvimento (média 4,9). Esse resultado corrobora com a afirmação de Gobeli e Brown (1994), de que as empresas que dão maior ênfase à pesquisa e desenvolvimento, são as que se orientam para a diferenciação.

Verificou-se ainda que as organizações que adotam um modelo de gestão de inovação padronizado são mais propensas à inovação por processos. Estudos têm indicado que empresas que possuem um modelo de gestão de inovação padronizado apresentam melhor desempenho (Kobe et al., 2005).

$\mathrm{Na}$ presente pesquisa, 29 empresas da amostra se destacaram quanto a esse quesito, sendo em sua maioria, exportadoras $(72,4 \%)$. Esse grupo de empresas são mais orientadas para a diferenciação (média 5,6), do que as organizações que não possuem um modelo de gestão de inovação padronizado. Essas empresas estão enquadradas nos seguintes setores industriais: indústria de produtos alimentícios, indústria de brinquedos, indústria têxtil, confecção e vestuário, elétrica e eletrônica, máquinas e equipamentos e indústria química.

Pode-se depreender disso, que a padronização é utilizada como um suporte da gestão da inovação, em termos de sua implementação (Wright et al., 2012), e reforça o uso da gestão da qualidade como uma das bases da estratégia de diferenciação, como citado acima.

Constatou-se que empresas que já possuem certificação ISO 9001 são as que apresentam melhor desempenho quanto à adoção de práticas de TQM Soft. Essas empresas representam $61,5 \%$ da amostra, totalizando 40 empresas. Destas, $42,5 \%$ são do setor elétrica e eletrônica, $17,5 \%$ do setor de máquinas e equipamentos, $15 \%$ da indústria de brinquedos, e demais, dos setores: aeroespacial, indústria química, utensílios domésticos, caldeiraria, têxtil, e de confecção e vestuário.

As empresas que ainda não possuem certificação ISO 9001, apresentaram as seguintes justificativas: "por que buscamos qualidade de produto, e não de processos" (setor de máquinas e equipamentos); “o resultado não justifica o investimento e manutenção desse tipo de sistema no mercado em que atuamos" (setor alimentício); "aplicamos sistema de qualidade de certificação baseada na NBR NM 300-3:2004" (indústria de brinquedos); "aplicamos o sistema 5 de qualidade do INMETRO" (indústria de brinquedos); "estamos nos preparando para a certificação" (setor de confecção e vestuário; setor de elétrica e eletrônica; indústria de brinquedos); "a empresa possui apenas a certificação PAS, emitida pelo SENAI - CE" (setor alimentício); "redução de custos" (setor de máquinas e equipamentos); “empresa nova, startup, será implementado no futuro" (setor de máquinas e equipamentos).

Os resultados sugerem que quanto maior o porte da empresa, maior o grau de adoção de práticas de qualidade, pois as empresas de grande porte se destacaram pelas maiores médias nas dimensões de práticas de qualidade.

\section{CONSIDERAÇÕES FINAIS}

O objetivo geral deste estudo foi analisar a relação entre orientação estratégica da empresa, práticas de gestão da qualidade e desempenho inovador no contexto de empresas brasileiras da indústria de transformação.

Respondendo ao primeiro objetivo específico deste estudo, foi constatado que apesar de predominar entre as empresas pesquisadas a adoção de práticas TQM Soft, com maiores médias, somente as práticas TQM Hard apresentaram impacto sobre a inovação por produto e por processo.

As práticas TQM Soft de maiores médias foram "planejamento estratégico" e "Comprometimento da alta administração", enquanto entre as práticas TQM Hard se destacaram "Design de Produto/Serviçoo", "Foco no Cliente" e "Gestão da Qualidade do fornecedor". Em geral, as médias revelaram que predomina nas empresas um desempenho médio e alto em termos de adoção de práticas de gestão da qualidade.

Esses resultados revelam que a qualidade possui um enfoque estratégico para as organizações pesquisadas, sendo usada como um meio de superação da concorrência na conquista da lealdade dos clientes, gerando um melhor desempenho inovador. Há um elevado envolvimento e suporte da alta administração da empresa com os planos e ações relativos à gestão da qualidade, cujas orientações voltadas para os clientes e processos, contribuem para a geração de vantagem competitiva.

No entanto, a média relativa à prática de benchmarking foi uma das mais baixas entre as organizações pesquisadas, principalmente as de pequeno porte. A prática de benchmarking deve ser incentivada entre as empresas, pois fomenta seu aprendizado e inovação contínua, a cada vez que se adaptam às melhores práticas do seu setor de atuação.

Quanto ao segundo objetivo da pesquisa, verificou-se que a estratégia de diferenciação é a que exerce maior influência sobre a inovação por produtos e a inovação por processos, apesar da maior média da amostra ter sido para a estratégia de liderança em custos. Com relação ao terceiro objetivo, observou-se uma maior associação entre a orientação estratégica 
para a diferenciação e as práticas de TQM Hard, do que com as práticas de TQM Soft.

Pode-se afirmar, portanto, que a gestão da qualidade é uma das bases de diferenciação das organizações pesquisadas, mesmo para as empresas ainda não certificadas pela ISO 9001. Elas buscam uma maior eficiência dos seus processos, não somente para reduzir custos, mas para gerar valor para o seu públicoalvo. Percebe-se que a resistência a certificação da gestão da qualidade pode estar associada aos custos de sua implantação e a existência de outros tipos de certificações, relativas a setores específicos, e mais voltadas à qualidade do produto.

A principal limitação desse estudo se refere ao tamanho da amostra,no entanto, acredita-se que seus resultados dão uma importante contribuição para o corpo de pesquisas sobre o tema.

\section{REFERÊNCIAS}

Abrunhosa, A., \& Sá, P. M. E. (2008, abril). Are TQM principles supporting innovation in the portuguese footwear industry? Technovation, 28 (4), 208-221.

Belohlav, J.A. (1993). Quality, strategy, and competitiveness.California management review, 35 (3), 55-69.

Bessant, J. et al.(2005). Managing innovation beyond the steady state. Technovation, 25 (12), 1366 1377.

Bigliardi, B.; Galati, F. (2014).The Implementation of TQM in $\mathrm{R} \& \mathrm{D}$ Environments. Journal of Technology Management \& Innovation, 9(2), 157171.

Boiral, O.(2012, julho).ISO 9000 and organizational effectiveness: a systematic review.QualityManagement Journal, 19 (3), p.1637.

Bsigroup. (2016). Mudando da ISO 9001:2008 para a ISO 9001:2015: guia de transição. Recuperado em 16 maio, 2016, de http://www.bsigroup.com/ptBR/ISO-9001-Gestao-da-Qualidade.

Conca, F. J., Llopis, J., \&Tarí, J. J. (2004).Development of a measure to assess quality management in certified firms. European journal of operational research, 156 (3),683-697.

Dahlgaard-Park, S. M. et al. (2013) Diagnosing and prognosticating the quality movement - a review on the 25 years quality literature (1987-2011). Total quality management \& business excellence, 24(12), 1-18.
Esperança, R. M. et al.(2015, julho-dezembro)Análise comparativa dos requisitos da norma ISO 9001:2008 com a ISO 9001:2015. Revista de Administração da FATEA, 11(11),84-95.

Fernandes, A. A. C. M., Lourenço, L. A. N., \& Silva, M. J. A. M. (2014, outubro-dezembro). Influência da gestão da qualidade no desempenho inovador. Revista brasileira de gestão de negócios, 16 (53), 575-593.

Field, A. (2009).Descobrindo a estatística usando SPSS. Porto Alegre: Artmed.

Fuentes, M.M. et al. (2006). Total quality management, strategic orientation and organizational performance: the case of spanish companies. Total quality management, 17(3), 303-323.

Gobeli, D.H.; Brown, W.B. (1994). Technological innovation strategies.Engineering management journal,6(1), 17-24.

Guerra, R. M. de A.,\&Tondolo, V. A. G. (2015, setembro-dezembro). Compreendendo a relação entre TQM HARD, SOFT e performance: uma abordagem teórica. Revista eletrônica de estratégia e negócios, 8(3),243-275.

Hoang, D. T., Igel, B., \&Laosirihongthong, T. (2006). The impact of total quality management on innovation: Findings from a developing country. International journal of quality and reliability management, 23 (9), 1092 - 1117.

Honarpour, A.,Jusoh, A.,\& Nor, K. M. (2012, setembro). Knowledge management, total quality management and innovation: a new look. Journal of technology management \& innovation, 7(3), 2231 .

Hung, R. Y. Y. et al. (2011, abril). Impact of TQM and organizational learning on innovation performance in the high-tech industry. International business review, 20(2), 213-225.

Kobe, C., Verworn, B., \& Meier, M. (2005). Implementation of innovation process models action research in Swiss companies. Anais do International Product Development Management Conference, Copenhagen, Denmark, 12.

Long, C.S. et al. (2015, maio). Impact of TQM practices on innovation performance among manufacturing companies in Malaysia. South african journal of industrial engineering, 26(1), 7585 . 
Philips, L.W., Chang, D.R., \&Buzzell, R.D. (1983). Product quality, cost position, and business performance: a test of some key hypotheses.Journal of marketing, 37(2),26-43.

Kim, D., Kumar, V., \& Kumar, U. (2012, maio).Relationship between quality management practices and innovation. Journal of Operations Management, v 30 (4), 295-315.

Krivokapic, Z. et al. (2013). A review and analysis concerning the effects of quality on innovation performance. International Journal for Quality Research, 7(1), 5-16.

Lakhe, R.R., \&Mohanty, R.P. (1994). Total quality management concepts, evolution and acceptability in developing economies. International Journal of Quality \& Reliability Management, 11(9), 9-33.

Leavengood, S. A., Anderson, T. R., \&Daim, T. U. (2016).Exploring Linkage of Quality Management to Innovation.Engineering and technology management faculty publications and presentations.paper 50. Recuperadoem 21 maio, 2016, http://pdxscholar.library.pdx.edu/etm_fac/50

Martínez-Costa, M., \& Martínez-Lorente, A. R (2008). Does quality management foster or hinder innovation? an empirical study of spanish companies. Total quality management \& business excellence, 19 (3), 209-221.

Miller, D. (1986). Configurations of strategy and structure: towards a synthesis. Strategic management journal,7(3), 233-249.

Mintzberg, H. et al. (2006).O processo da estratégia: conceitos, contextos e casos selecionados. Porto Alegre: Bookman.

Nair, A. Meta-analysis of the relationship between quality management practices and firm performance: implications for quality management theory development (2006, dezembro). Journal of operations management, 24 (6), 948-975.

Pekovic, S., \&Galia, F. (2009). From quality to innovation: evidence from two french employer surveys. Technovation, 29(12), 829-842.

Pereira-Moliner, J. et al. (2016). Organizational design, quality management and competitive advantage in hotels, International Journal of Contemporary Hospitality Management, 28 (4), 762-784.

Pires, A. F. E. (2013).Determinantes da inovação no desempenho inovador: influência das fontes de informação, da cooperação e dos investimentos e despesas de inovação. Dissertação de Mestrado, Instituto Politécnico de Tomar, Portugal.

Prajogo, D.I. (2007). The relationship between competitive strategies and product quality. Industrial management \& data systems, 107(1), 6983.

Prajogo, D.I., \&Sohal, A.S.(2001).TQM and innovation: a literature review and research framework. Technovation, 21(9), 539-558.

Prajogo, D.I., \&Sohal, A.S.(2003). The relationship between TQM practices, quality performance, and innovation performance: an empirical examination. International journal of quality \& reliability management, 20 (8), 901-918.

Prajogo, D.I., \&Sohal, A.S. (2004, junho). The multidimensionality of TQM practices in determining quality and innovation performance: an empirical examination. Technovation, 24(6), 443453.

Prajogo, D.I., \&Sohal, A.S. (2006, janeiro). The relationship between organization strategy, total quality management (TQM), and organization performance: the mediating role of TQM. European journal of operational research, 168 (1), 35-50.

Prajogo, D.I., \& Hong, S. W. (2008, dezembro).The effect of TQM on performance in R\&D environments: a perspective from South Korean firms. Technovation, 28 (12), 855-863.

Reed, R., Lemak, D.J., \&Montgomery, J.C. (1996). Beyond process: TQM content and firm performance. Academy of Management Review, 21 (1), 173-202.

Ruiz-Moreno, A. et al.(2016).Quality management and administrative innovation as firms' capacity to adapt to their environment.Total Quality Management \& Business Excellence, 27(1-2), 48-63.

Sadikoglu, E.,\&Olcay, H. (2010). Investigating the effects of innovation and employee performance on the relationship between total quality management practices and firm performance: an empirical study of Turkish firms. International journal of production economics, 127(1), p. 13-26.

Sadikoglu, E.,\&Olcay, H. (2014, janeiro). The effects of total quality management practices on performance and the reasons of and the barriers to TQM practices in Turkey. Advances in Decision Sciences, 1-17. 
Santos-Vijande, M. L., \&Álvarez-González, L. I.(2007).Innovativeness and organizational innovation in total quality oriented firms: The moderating role of market turbulence. Technovation, 27(9), 514-532.

Sousa, R., \& Voss, C. A.(2002).Quality management re-visited: a reflective review and agenda for future research. Journal of Operations Management, 20 (1),91-109.

Silva, G. M. et al. (2014). The role of TQM in strategic product innovation: an empirical assessment. International journal of operations \& production management, 34(10), 1307-1337, 2014.

Sinha, N.,Garg, A. K., \&Dhall, N. (2016).Effect of TQM principles on performance of Indian SMEs: the case of automotive supply chain. The TQM Journal, 28 (3), 338-359.

Talib, F. (2013). An overview of total quality management: understanding the fundamentals in service organization. International journal of advanced quality management, 1(1), 1-20.

Talib, F., Rahman, Z., \& Qureshi, M.N. (2013).An empirical investigation of relationship between total quality management practices and quality performance in Indian service companies. International journal of quality \& reliability management, 30 (3), 280-318.

Tan, Boon-In. et al. (2014). Soft TQM practices, customer orientation and business performance: a proposed structural model. International journal of modelling in operations management,4(1-2), 21-34.

Terziovski, M.; Guerrero, J. (2014, dezembro).ISO 9000 quality system certification and its impact on product and process innovation performance. Internationaljournalofproductioneconomics, 158 (1), 197-207.
Toledo, A. G. L., \& Bandeira-de-Mello, R. (2013, junho). Criação de valor: incorporando elementos da economia dos custos de transação na visão porteriana. Revista de administração contemporânea, 17(3), 285-303.

Vahidnia, F., Bavarsad, B., \&Senoubari, M. (2013).Impact of TQM on innovation performance whit the mediating rol organizational learning of studiyilam industrial town. Advances in environmental biology, 7 (9), 2535-2540.

Zatzick ,C.D., Moliterno,T.P., \&Fang,T. (2012). Strategic(mis)fit:theimplementationofTQM in manufacturing organizations.Strategic Management Journal,33 (11), 1321-1330.

Zhang, D., Linderman, K., \&Schroeder, R. G. (2014, fevereiro). Customizing quality management practices: a conceptual and measurement framework. Decision sciences, 45(1), 81-114.

Zeng, J., Phan, C. A., \& Matsui, Y. The impact of hard and soft quality management on quality and innovation performance: an empirical study. International journal of production economics, 162 (1), 216-226.

Wong, C., Lee, H. Linking a tridimensional linkage of TQM, SCM and organisational performance: a proposed conceptual framework. International journal of modelling in operations management, 4 (1-2), 2014.

Wright, C., Sturdy, A., \& Wylie, N.(2012). Management innovation through standardization: Consultants as standardizers of organizational practice. Research Policy, 41(3), 652-662.

Yusr, M. M., Mokhtar, S. S. M., \& Othman, A. R. (2014, junho). The effect of TQM practices on technological innovation capabilities: applying on Malaysian manufacturing sector. International journal for quality research, 8(2), 197-216. 